\title{
PELUANG DAN TANTANGAN FORMULASI METODE STUDI ISLAM
}

\begin{abstract}
Asmavi*
Abstract: In speaking of Idamic studies, we need to remember two things First is the approah by which wedaboratecetain pintfrom cetain perspeetive. In Isamicstudies-like in any other studies approahes vary. Different approadhes would bringdifferent condusions Howeer, as longasan approachisacadenicallysaundand acceptableandmetsall standards requireed, any condusion resilted thereen is deemed comet and justifiable Hence, no singe condusionisconsideredright whilethedher is wrong Isamicstudies should theeforeadknowleelge that acaderic truth is not singular but plural on the ground that there are many approadhes tovard many condusions. It is this notion that we want to disass here We are interested in exploing thendion of intelletual truth Wehold that differences in qinion should beacepted as natural. Secondis, that thereisnofindanmental differenes in thebasic valuef sienesof anykinds Inctherwords what ispopularlyknownasWestemsienreand Idamic sience does not in prinaple differ. Saience is sience There cannot bea didhotomy between Idamicor non-Isamicsaence Didhotamy insienceis not aceptable Saienebdangs to all alture, tradition and reigion It dbes not knowpartiallarity. It is univessal. Idamic studies should undestand this and useall tods, approaches mothoddojes -albit Westemfor their improvenet. It istoward theseissues that this paper is destined
\end{abstract}

Keywords: Idamicstudies, didhotomy, integrativemthod

\section{Pendahuluan}

Pendekatan studi Islam adalah wacana yang menarik dalam diskursus ilmu-ilmu keislaman, karena berkaitan langsung dengan sentuhan nilai ilahiyah yang merupakan fundamental value bagi umat Muslim, juga berhubungan dengan realitas hidup berbangsa, bernegara dan beragama yang di dalamnya rentan dengan nilai-nilai kemasyarakatan yang kadang dipahami berjarak bahkan dipisahkan sama sekali. D alam dasawarsa terakhir, perkembangan metode kajian Islam mengalami kemajuan yang signifikan, di samping karena adanya warisan klasik kesarjanaan muslim yang hingga kini masih eksis, juga diakibatkan baik langsung atau tidak langsung dengan tradisi keilmuan Barat yang telah lebih dahulu maju dalam berbagai disiplin ilmu. Misalnya wacana studi Islam di Belanda, yang menurut Sjoerd van Koningsveld, studi Islam di Belanda sudah tidak lagi mempermasalahkan mengenai wilayah studi Islam karena para Orientalis menganggap bahwa hal tersebut sudah final. ${ }^{1}$ Mereka lebih menitik beratkan pada pendekatan studi pada ilmu-ilmu bantu yang diperlukan dalam mengkaji Islam, sehingga studi Islam di Belanda tidak lagi mempermasalahkan beberapa ilmu umum yang kita kenal selama ini juga menjadi kawasan studi Islam. ${ }^{2}$ Ini artinya mereka lebih conempada kemajuan ilmu pengetahuan yang nyata, yang secara ilmiyah dapat dipetanggung jawabkan, ketimbang mengkaji wilayah studi Islam.

\footnotetext{
* Sekolah Tinggi Agama Islam (STAIN) Tulungagung, Jawa Timur "Jacques Wandenburg, "Studi Islam di Belanda", dalam Nanji Azim. ed. PeaStudi IsamOrientalismedanArahBaru KajianIsamdi Barat(Bantul: FajarPustaka Baru, 2003), 114.

${ }^{2}$ Ibid.
} 
Persepsi mereka tidak jauh berbeda dengan apa yang telah dibakukan oleh dan dipelajari di sebagian lingkungan para pemikir Muslim selama ini, atau secara keindonesiaan beberapa Perguruan Tinggi Agama Islam (PTAI). Namun demikian mereka tetap menganggap penting bahwa ilmu-ilmu tersebut secara metodologis harus didekati dan diapresiasi dengan berbagai ilmu bantu, seperti filsafat, sosiologi, fenomenologi, sejarah antropologi, psikologi dan lain sebagainya. D engan ilmu bantu ini diharapkan pantulan empiris dari wajah Islam semakin nampak jelas.

Mumtaz Ali mengatakan, There was a need to disass and explain it detail how a msim studat, in Idamic Thought, in natural sienes and in human scienes, can aply the priniples of empinism howhe can benfit frompragnatig priniples What are the primiples of an Isamic mothoodlogy that can provide the sustainable premise upon which an Islamic dsaipline in human siences can deddoped.? Even today we donot have Islamically oriented text books which can be used in modem Isamic Univesities in the MusimWold Weall knowas educationist that no educational system can be succesul withat proper armialumand syllabi3

D alam hal ini, persoalan yang mendesak untuk dipecahkan adalah menemukan cetak biru metodologi studi Islam. Sebab harus diakui bahwa studi Islam (Isamic studies) adalah salah satu studi yang mendapatkan perhatian di kalangan ilmuwan. Di samping itu studi Islam mulai banyak dikaji oleh para peminat studi agama dan studi-studi lainnya. ${ }^{4} \mathrm{Di}$ sini pantas untuk dikatakan bahwa studi Islam layak untuk dijadikan sebagai salah satu cabang favorit. D engan kata lain studi Islam telah mendapat tempat dalam percaturan dunia ilmu pengetahuan di berbagai Universitas di D unia ini. ${ }^{5}$

Untuk itu masalah yang urgent untuk segera dipecahkan adalah masalah metodologi atau pendekatan dalam studi Islam. Hal ini disebabkan karena kelemahan di kalangan umat Islam dalam mengkaji Islam secara komprehensif adalah tidak menguasai metode pendekatan atau metodologi. ${ }^{6}$ Kelamahan ini semakin kelihatan manakala umat Islam tidak menjadi produsen pemikiran, tetapi menjadi konsumen pemikiran. ${ }^{7}$ D alam kasus di Indonesia kalaupun ada pemikiran dari internal pemikir Muslim sifatnya hanya dkletis tidak menampilkan orginalitas sebuah pemikiran dan penemuan, juga disebabkan karena kurangnya kemampuan di bidang metode pendekatan atau metodologi dalam Idamic sudes

Di samping itu, ada anggapan bahwa studi Islam di kalangan ilmuwan telah merambah ke berbagai wilayah. Misalnya studi Islam sudah masuk studi kawasan, filologi, dialog Agama,

\footnotetext{
${ }^{3}$ Mohammad Mumtaz Ali, "Recontruction of Islamic Thought and Civilization: An Analitycal Study of The Movement for The Islamization of Knowledge," dalam IdamicQuartdy, Vol. XLII, No. 1. (1999), 28-29.

${ }^{4} \mathrm{~K}$ amal Hasan dalam salah satu tulisannya menyebutkan bahwa: "Muslim student in public universities are also exposed to few courses on Islam, while come Chatolic and Protestant Universities provided own course on Islamologi. Mohd. Kamal Hasan. "Islamic Studies In Contemporary South East Asia: General O bservation," dalam Ismaelee (et.al), (ed), Isamic Studies in Asean (Thailand: College of Islamic Studies, Prince of Sonkla University, 2000), 481. Lihat juga!. Zainudin Fanani dan M. Toyibi (terj), Studi IsamA sia tenggara (Surakarta: Muhamadiyah University Press, 1999), 153-224. Kamaruzaman Bustaman A hmad, Isamhistaris, DinamikaStudi Isamdi Indanesia (Yogjakarta: G alang Press, 2002), 3-20.

${ }^{5}$ Maksudnya studi Islam sudah menjadi kerangka dasar dalam kajian akademik. Louay Safi, TheFaundation of Knoweedge A ComparativeStudyinIsamicandWeternMethodeof Inquiry(Malaysia: International Islamic Universwity Malaysia Press, 1996).

${ }^{6}$ Harun Nasution. "Metodologi Barat Lebih Unggul" dalam Ulumal-Qur'an No. 3, Vol. V. (1994), 27-30.

${ }^{7}$ Nurcholis Majid, Tradis Idam PerandanFunginya dalamPenbangumanIndonesia(Jakarta: Paramadinja, 1997), 3-11.
} 
dan sebagainya. ${ }^{8} \mathrm{~K}$ arenanya metode dan pendekatan yang sesuai adalah suatu keharusan yang mesti dikuasai oleh peneliti (rearche) Islam.

Tulisan ini akan menjelaskan beberapa tawaran metode pendekatan studi Islam dari berbagai disiplin ilmu: yakni pendekatan filsafat, pendekatan sosiologi, pendekatan sejarah, pendekatan hermenetika, pendekatan fenomenologi, yang tergabung dalam paradigma dikotomisatomistik ${ }^{9}$ dan kemudian diakhiri dengan paradigma integatif-intekanktif sebagai terobosan baru dalam mengkaji dan meneliti masalah-masalah keislaman.

\section{Alternatif Pendekatan Studi Islam}

Berikut ini akan diketengahkan beberapa pendekatan yang dapat digunakan dalam Studi Islam. Untuk model pertama yaitu pendkatan filsafat. Pendekatan filasat secara umum, terutama dalam pembuatan klasifikasi hubungan antara perkembangan ilmu pengetahuan dalam menatap alam semesta (manusia, hewan, tumbuh-tumbuhan, ruang angkasa) dan pengembangan wilayah pengalaman spiritual manusia. ${ }^{10}$ Masukan-masukan yang disumbangkan oleh pendekatan filsafat ilmu akan memunculkan knitishistais terhadap bangunan ilmu pengetahuan, baik yang disebut sebagai ilmu-ilmu keagamaan maupun ilmuilmu yang lain sehingga mendapat perhatian yang proposional.

Pendekatan semacam ini dapat menggunakan beberapa teori para pakar filsafat ilmu kontemporer seperti Karl R. Popper dengan Contexs of Justificationatau Contexs of Discovery, atau dalam bahasa Kuhn dengan teori Nomml Saience atau Revolutionary Säences, Lakatos dengan Reserch Programenya yang berisi tentang hard care (ajaran inti) dan protedive bett (pengaman ajaran intinya). ${ }^{11} \mathrm{D}$ alam bahasa pakar filsafat Indonesia dalam suatu agama mempunyai dua unsure; yaitu unsur sakralitas (taqdisal-afkaral-driiyahdan profan (muannlah ma' al-nas). Kedua unsur tersebut jika dikaitkan dalam studi Islam maka al-Q ur'an dan $\mathrm{H}_{\text {đadith }}$ merupakan sumber yang pertama. Adapun selain kedua hal tersebut disebut dengan unsur profan. Pada dasarnya pendekatan ini menurutnya memiliki sifat keilmuan, inklusif dan terbuka. Dari ketiga sifat ini, tampaknya sangat tepat untuk menjadikan filsafat sebagai salah satu pendekatan dalam studi Islam. Lebih lanjut filsafat sebagai metodologi keilmuan ditandai dengan tiga ciri, 1). Pendekatan kajian atau telaah filsafat selalu terarah pada

\footnotetext{
${ }^{8} \mathrm{~K}$ amaruzaman Bustaman Ahmad, IsamHistars 3-20. Penjelasan tentang hal ini lihat! Misalnya. Mehdi G olshani. "Islam and The Science of Nature:Some Funjdamental Question, IdamicStudes Vol. 39, No. 4. (2000), 597-611. W.A.L. Stokhof dan N.J.G. K aptein (Red). Beberapa Kajian Indonesia dan Isam(Jakarta: INIS, 1990), Matulada. "Studi Islam Kontemporer: Sintesis Pendekatan Sejarah, Sosiologi dan Antropologi dalam Mengkaji Fenomena Keagamaa," dalam Taufiq Abdulah dan M. Rusli K arim, ed., Mecoblog Penditiagn Agama: Sebuah Pengantar (Yogjakarta: Tiara Wacana, 1989), 1-13. Abudin Nata, Młoodøg Stud ISam(Jakarta: Raja Grafindo Persada, 1999), Rifaat Syauqi Nawawi, Meodbog Psikdoj Idami(Yogjakarta: Pustaka Pelajar, 2000). Amin Abdullah dalam bukunya yang terakhir IdamicSudiesdi Pergunan Tingg: : PendkatanDikotamisAtomistik-Integratif-Intekanktif (Yogjakarta: Pustaka Pelajar, 2006). Amin Abdullah, FalsafahKalamdi EraPot Modamisme(Y ogjakarta: Pustaka Pelajar, 1995), Amin Abdullah, Studi Agama. NomativitasatauHistoristas(Yogjakarta: Pustaka Pelajar, 1996).

${ }^{9}$ Dikotomis-A tomistik dan Integratif-Interkonektif meminjam istilah Amin Abdullah dalam bukunya yang terakhir IsamicStudiesdi PergunanTinggi mulai dari pendekatan D ikotomis A tomistik sampai kepada IntegratifInterkonektif (Yogjakarta: Pustaka Pelajar, 2006). 361-399.

${ }^{10}$ Seyyed Hosein Nasr, KnowkedgeandTheSacred (Pakistan: Suhail Akademy Lahore, 1988), 75 - 95.

${ }^{11}$ Thomas Kuhn, TheStructure of SaientificRedution(Chicago: University of Chicago Press, 1970), 23-24. Imre Lakatos, "Falsification and The MethodologyoOf Scienctific Research Programes", dalam CritiosmandTheGrow of Knowkeage, ed. Imre Lakatos and Alan Musgrave, (Cambridge : Cambridge University Presss, 1970), 132-138. Karl R. Popper, TheLogicof SaientificDiscoery(London: Unwin Hymann, 1987).
} 
pencarian dan perumusan ide-ide atau gagasan yang bersifat mendasar-fundamental (fundamental idkas) dalam berbagai persoalan. 2). Pengenalan dan pendalaman persoalan-persoalan serta isu-isu fundamental dapat membentuk cara berfikir yang bersifat kritis (citical thought), 3). Kajian dan pendekatan filsafat yang bersifat demikian secara otomatis akan membentuk mentalitas cara berpikir dan kepribadian yang mengutamakan kebebasan intelektual (intddktual freedom) sekaligus mempnyai sikap toleran terhadap berbagai pandangan dan kepercayaan yang berbeda serta terbebas dari dogmatis dan fanatisme. ${ }^{12}$

Pemikir Muslim yang mencoba mengapresiasi pendekatan filsafat dalam studi Islam

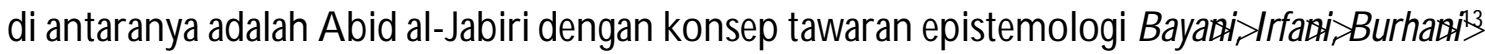
dan Khalid Abu al-Fadl yang menawarkan tentang herneutika fatwa-fatwa keagamaan. ${ }^{14}$ Hermenutika yang ia tawarkan berbeda dengan apa yang sudah ditawarkan oleh Fazlurahman, Farid Essack, Nashr Hamid Abu Zaid. Kajian yang ditawarkan bersifat multidisipliner lantaran melibatkan pendekatan dari berbagai keilmuan seperti, lingsitik, interptative soial saience, literary ditiosm selain ilmu-ilmu keislaman yang telah baku misalnya 'ulumal-hadith, fiqh usklpal- fiqh ilmu tafsir maupun kalam.

Dengan konsepnya tersebut Khalid ingin mengembalikan ilmu yurisprudensi Islam sebagai sebuah epistemologi dan sekaligus sebagi metode penelitian, bukan sebagai keilmuan Islam yang beraroma politis dan otoriter. ${ }^{15}$ Di dalamnya tersebut ada semacam integrasi antara intdect, intuition dan the moral yang sudah dicetuskan oleh ulama-ulama klasik dan dikembangkan dengan beberapa pendekatan kontemporer.

Pendekatan selajutnya adalah pendekatan Sosiologi. Ada beberapa tokoh sosiologi yang menawarkan beberapa ide terkait dengan A gama, di antaranya adalah E mile D urkheim, dengan paradigma positifistiknya. Sebagaimana August Comte (penggagas positivisme dalam sosiologi), mengutarakan sebuah pertanyaan what Reigion does? apa fungsi yang dijalankan agama yang telah melalui proses institusionalisasi. Durkheim merumuskan bahwa yang menjadi kajian bagi sosiologi adalah Fakta Sosial, dengan asumsi yang mendasari pengkajian agama secara sosiologis. Ia menegaskan All the ensial dements of religias thangt andlifearght to be found, at least in gem in most primitif religion ${ }^{16}$ O leh karenanya bagi $D$ urkheim dalam rangka mencermati agama seseorang harus melakukan studi terhadap agama yang paling sederhana, yaitu agama primitif, dan itu dapat dijumpai pada masyarakat primitif pula. Contoh yang ia kemukakan adalah suku Aborigin di Australia sebagai bentuk keberagamaan paling elementer. D engan meneliti ini akan kelihatan bahwa upacara Totem mempunyai fungsi sebagai sarana meneguhkan ikatan kekeluargaan di antara komunitas suku Aborigin. Sebagaimana Durkheim menegaskan bahwa kehidupan bersama itu berlandaskan kepada

\footnotetext{
${ }^{12}$ Amin Abdullah, "Relevansi Studi Agama-Agama Pada Millenium Ketiga," dalam Amin Abdullah dkk, Menari Isam Studi Isamdangan Bebagai Pendkkatan 7-8. Lihat Juga A min Abdullah, Falsafah Kalamdi EraPost Modknisme Idem. Idamic Studien d Perguruan Tingg;, Pendkatan DikotomisA tomisticIntegraqtif Intekonktif

${ }^{13}$ Muhamad Abid al-Jabiri, Takninal-'Aqdi al-'ArabiłBeirut: Markaz Dirasah al-Wihdah al-'Arabiyah, 1989). AlJabiri, al-Aql al-Siyasiz-'Arabi (Beirut: Markaz al-Thaqafi al-'Arabi, 1991). Al-Jabiri, Bunyatal-Aqli al-'Arabi: Dirasoh TabliliyahNaqdiyahli Nuzlmmal-Ma'nifahfi al-Thaqafahal-'Arabiyah(Beirut: Markaz dirasah al-Wihdah al-'Arabiyah, 1990).

${ }^{14}$ Khalid A bu Fadhl, SpeakinginGodsName IslamicLawAuthorityandWomen(O xford: O ne World Publication, 2001).

${ }^{15}$ Amin Abdullah, IsamicStudies, 72-285.

${ }^{16}$ Steven Lukes, EmileDurkhemm HisLifeandWork(London: Pinguin Book, 1992), 9-13.
} 
kesadaran kolektif (collectiveconiasnes), maka ritual agama pada dasarnya merupakan jalan mengasah kesadaran kolektif ini. ${ }^{17}$

Konsep sosiologi agama dilanjutkan oleh Weber dengan menggagas bahwa yang menjadi obyek kajian sosiologi bukanlah Fakta Sosial melainkan Aksi Sosial. Dalam kajian agama dengan pendekatan sosiologis, paradigma Weberian berangkat dari pertanyaan what reiginis? . Kalau D urkheim dianggap mendefinisikan agama secara fungsional, maka Weber secara substansial. Tugas Sosiologi Agama adalah mengungkap makna religius dari setiap aksi sosial manusia.

D emikian juga Karl Max melihat agama dengan pisau analisa historis-materialistis kemudian beranggapan bahwa kehidupan materilah yang mempengaruhi segala aspek hidup dan kehidupan manusia. D alam tradisi sosiologi agama, paradigma Marxian cenderung melihat agama dan menganalisanya sesuai dengan sejauh mana agama yang hidup di masyarakat itu berpihak kepada kelas yang ada. Misalnya negara melalui agen-agennya mengkhutbahkan ayat-ayat Tuhan menjustifikasi kekuasaannya, suatu kecenderungan yang sangat tampak pada realitas kehidupan kekinian.

Berbeda dengan ketiga pendahulunya Clifford G eertz melihat agama sebagai simbol. ${ }^{18}$ Yang berfungsi sebagai due pint untuk memahami dunia yang ditangkap manusia dalam alam budayanya. Simbol religius disebut sebagai macosymbdic yang membantu seseorang untuk menerjemahkan maknakehidupan dan menyediakan kosmologi atau pandangan hidup.

D alam hal studi Islam, ilmuwan Indonesia yang mencoba memasukkan pendekatan sosiologi ke dalam studi Islam adalah Atho' Muhdzar. Dia menjelaskan Studi Islam dengan pendekatan sosiologi dapat mengambil beberapa tema: petama, studi tentang pengaruh Agama terhadap masyarakat atau lebih tepatnya pengaruh agama terhadap perubahan masyarakat. ${ }^{19}$ Teori ini mengingatkan kepada D urkheim yang memperkenalkan konsep fungsi sosial dari agama. ${ }^{20}$ D alam bentuk ini studi Islam mencoba memahami seberapa jauh polapola budaya masyarakat berpangkal dari nila-nilai agama, atau seberapa jauh struktur masyarakat (seperti supremasi laki-laki) berpangkal dari ajaran agama atau seberapa jauh perilaku masyarakat berpangkal pada suatu ajaran agama. Kedua, studi tentang pengaruh struktur dan perubahan masyarakat terhadap pemahaman ajaran Agama atau konsep keagamaan. ${ }^{21}$ Ketiga, studi tentang tingkat pengalaman beragama masyarakat. Studi Islam dengan pendekatan sosiologi dapat mengevaluasi pola penyebaran agama dan seberapa jauh agama itu diamalkan oleh masyarakat. Seberapa jauh mereka misalnya melakukan ritual sesuai ajaran agama, ajaran zakat, haji, dan sebagainya. ${ }^{22}$ Informasi ini diperlukan terutama

\footnotetext{
${ }^{17}$ Ibid., 458.

${ }^{18}$ Clifford G eertz, TheInterpretationof Culture SetetedEssays(New York: Basic Book, 1973), 90.

${ }^{19}$ Ibid.

${ }^{20}$ Paradigma Sosiologi A gama yang ditawarkan Durkheim beranjak dari Positifistik August Comte. D engan mengajukan pertanyaan What ReigionDos?, A pa fungsi dari agama?. D urkheim dalam konsepnya menjelaskan bahwa para ahli Sosiologi Modern telah mengidentifikasi fungsi-fungsi sosial Agama, yaitu: Fungsi Solidaritas Sosial, Memberi Arti Hidup, Kontrol Sosial, Perubahan Sosial, dan D ukungan Psikologis. Nadhir Salahudin, "Peta Kajian Islam di Indonesia", dalam Jumal Akaderika, Program Pascasarjana IAIN Sunan Ampel Surabaya, Volume 05, Nomor 1, September 1999, 27.. Steven Lukes, EmileDurkhimm 9 -13. Atho Mudzhar. "Studi Agama dengan Pendekatan Sosiologi dalam Amin Abdullah dkk., Mencan Isam 60.

${ }^{21}$ Ibid.,31.

${ }^{22}$ A tho Mudzhar. "Studi Islam, 30.
} 
oleh dan pengembang masyarakat. Keempat. Studi pola sosial masyarakat Muslim. Yakni pola-pola perilaku masyarakat Muslim kota dan desa, pola hubungan antar agama dalam masyarakat, pola perilaku masyarakat muslim terdidik dan kurang terdidik. Demikianlah seterusnya sepanjang studi perilaku itu menyangkut orang-orang Islam sudah dapat dikatagorikan studi Islam. ${ }^{23}$ Keima Studi tentang gerakan masyarakat yang membawa paham yang dapat melemahkan atau menunjang kehidupan beragama ${ }^{24}$ Setelah itu A tho' Muhdzar mencoba pendekatan sosiologi ini dalam studi hukum Islam yang dipandang sebagai gejala sosial, yang pada giliranya mampu menjelaskan fenomena sosial menurut hukum Islam.

Pendekatan sejarah diajukan oleh D evin D ewees dan O mit Safi ${ }^{25}$ yang dalam tulisan keduanya tersebut menggambarkan adanya analisa sejarah yang sangat kritis sehingga dapat menjelaskan beberapa hal penting dalam pendekatan sejarah, yaitu: petama, Sumber tulisan diambilkan dari sumber yang berhubungan langsung dengan data di lapangan, sehingga dapat menampakkan dua unsur pokok dari analisa sejarah yaitu konsep periodsasi dan rekonstruksi proses genesis sebuah perilaku sejarah atau originalitasnya yang berakibat kepada perubahan (dhange) dan perkembangan sejarah (dadqpmet). Keelua, dapat menampilkan koherensi sebuah kisah antara teori-teori sejarah dengan praktek realitas sebagai tempat publik. Di dalamnya diidentifikasi terdapat banyak kepentingan yang terjadi akibat interaksi sosial masyarakat. Baik berupa patronase kekuasaan, rutinitas ritual atau yang lainnya. Ketiga, konsistensi logik alur sejarah dalam sebuah cerita sejarah sangat diperlukan, sehingga ketika asal usul sejarah dieksplorasi dapat menangkap bahwa perilaku sejarah tersebut sebenarnya telah bercampur dengan tradisi, apalagi ketika proses sejarah telah menjadi tempat publik dalam rangka legenda Islamisasi dalam sebuah komunal tertentu. ${ }^{26}$

Selain tokoh di atas yang mengembangkan pendekatan sejarah ini adalah Josep van Ess dan D avid S Powers dengan konsep struktur logika ilmu kalam ${ }^{27}$ dan Hukum Islam. ${ }^{28}$

Sementara itu pendekatan psikologi diutarakan oleh Dan Merkurr dengan menggabungkan antara ilmu psikologi dengan ilmu-ilmu agama. Menurutnya Psikologi Agama adalah mempelajari fenomena agama sebatas ia bisa dijelaskan secara psikologis, Psikologi agama merupakan istilah yang memayungi mazhab pemikiran: Acadamic sudy of religion, Academic psychdogy, Psychoamalysis, Analytic psychdogy, Transpessonal psydhlogy.

Psikologi agama merupakan reduksi terhadap agama ke dalam psikologi dan tujuan pendekatan dan riset psikologi merupakan alat untuk pemurnian agama dari pemujaan berhala. Konsepnya tentang psikologi agama adalah ColletiveUnconsiaus and theArdheypes (C.G. Jung) Pessana; yakni menutupi ego dan menyampaikan wajah yang terbaik pada dunia.

${ }^{23}$ Ibid.

${ }^{24}$ Ibid.

25D evin D ewees," Sacred Places and Public Narratives: The Shrine of Ahmad Yasafi in Hagiographical Tradition of The Yasafi Sufi O rder, 16-17 Centuries", dalam MusimWodd 2000, Volume. 90. O mit Safi, "Bargaining with Barakah: Persian Sufism Mysticism and Pre Modern Politics," dalam MusimWodd 2000, Volume. 90, 259-286. ${ }^{26}$ Ibid.

${ }^{27}$ Josep van Ess. "The Beginning of Islamic Theology" dalam J.E Murdoch and E.D Stylla (ed), TheCultural Contex of Medival Leaming(D ordrec-Holland: Reidel Publishing, 1975). Josep van Ess, "The Logical Sructure of Islamic Theology", dalam Issa Boullata(ed), An Ontdogy of IsamicTheology (Canada: Mc Gill Indonesia IAIN Development Project, 1992).

${ }^{28}$ D avid S. Powers, Peralihan Kkkayaan dan Pditik kdkuasaan: Kritik Historis HukumWanis terj. Arif Maftuhin (Yogjakarta: LKiS, 2001), viii dan 1-47. 
Animss yaitu aspek kelelakian pada wanita, Anima ialah aspek kewanitaan pada laki-laki dan Shadowadalah bagian dari pribadi di luar kesadaran.

Pendekatan fenomenologi banyakjuga menarik perhatian orang. Pndekatan ini diajukan di antaranya oleh D ogles Allen yang ingin berusaha mempertemukan antara ilmu filsafat dengan disiplin ilmu lain, di antaranya dengan psikologi sehingga melahirkan fenomenologi psikologi, atau dengan agama sehingga melahirkan fenomenologi agama. Agama dalam perspektif Barat pada masa awal didekatati dengan berbagai disiplin; di antaranya pada mulanya dengan asal-susul (arign) yang berbentuk normatif, descivtiv normatif apologetik, sampai kepada development yaitu berupa kesadaran murni (transendental inteletuality dari pengalaman keagamaan. ${ }^{29}$

Ini kemudian direspon oleh Abdul Rauf yang memberikan pandangan yang irenic (simpatik) kepada atsider, namun tetap memberikan syarat kejujuran agar Islamis Barat sampai kepada kesimpulan yang terhindar dari kesalahan dalam menyimpulkan tentang Islam. ${ }^{30}$ Sedangkan Fazlurahman menjelaskan lebih mendalam dan luas tentang persyaratan jujur yang tidak berprasangka, terbuka dan instrumennya dapat dipercaya, bahkan dia menyambut fenomenologi selama al-Qur'an dan al-Sunnah sebagai rujukan normatif. ${ }^{31}$ Pendapat Rahman ini juga diamini oleh Richard C. Martin dalam tulisanya Approades to Islamin ReigionsStudies D ia mengatakan tradisi orientalisme dengan menekankan pendekatan historis-filologis tidak akan dapat lepas dari kepentingan ideologis yang kemudian akan berpengaruh terhadap pemahaman yang dihasilkan. Untuk itu kedua pendekatan ini belum mencukupi untuk mengkaji tradidisi keagamaan secara otentik dan empatik, disebabkan melihat tradisi keagamaan dari aspek-aspek eksternal. Pendekatan Phenomendogy of reigion diupayakan dapat menjembatani tensionantara dimensi historis-empiris-partikular dari agamaagama dan aspek makna keagamaan umat manusia yang mendasar dan universaltransendental..$^{32}$

D ari beberapa pendapat tentang fenomenologi tersebut diharapkan dapat membangun kerangka berpikir logic (frame of logid yang tidak hanya bersumber dari asumsi, aksioma, pandangan normatif subyektif, tetapi juga harus memperhatikan realitas yang menjadi obyek kajian. Juga dalam melihat fenomena agama tidak cukup didekati dengan satu pendekatan tetapi harus holistik, integral dengan disiplin ilmu lain, sehingga kajian agama akan selalu kontekstual.

Dalam hubungannya dengan pendekatan studi Islam dan pengembangan keilmuan Islam semacam beberapa tawaran disiplin ilmu di atas, meminjam teori dari Amin Abdullah masih berupa tawaran pendekatan yang dikotomis-atomistik. Artinya, kita masih

\footnotetext{
${ }^{29}$ D ougles Allen,"Phenomenologi of Religion," dalam TheRatleage CompaniontoTheStudy ofRdigion ed. John R. Hinnels, (G reat Britian: Routledge, tt) 182-189. Francois Loytard, Phenomendog (New York: State University Of New York Press, 1991), 9.

${ }^{30}$ Muhamad Abdul Rauf, "Interpretasi O rang Luar tentang Islam," dalam Richard Martin, PendkatanKajianIsam dalamStudi Agama, 240-247.

${ }^{31}$ Fazlurahman, "Pendekatan dalam Islam dalam Studi Agama," dalam Richard Martin, PendkkatanKajianIsam dalamStudi Agama, 249-256.

${ }^{32}$ Richard C. Martin. ed., ApproarchestoIsamin RdigausStudies(Tucson: The Arizona State University, 1985), 1-18. Juga C. Martin, Pendkkatan KajianIdamdalamStudi Agama, terj. Z akiyudin Bhaidawi (Surakarta: Muhamadiyah University Press, 2002).
} 
mengklasifikasikan beberapa keilmuan yang ada mulai dari natural siences, human sciences dan soial siences secara terpisah dan digunakan dalam wilayah masing-masing, maka sudah waktunya ada upaya menggabungkan (integrasi) epistemologi keilmuan umum dan agama dengan mengadakan dialektika dan kerjasama antara disiplin ilmu.

Paradigma dikotomis atomistik, ${ }^{33}$ aspek kehidupan dipandang dengan sangat sederhana ${ }^{34}$ Segala sesuatu dilihat dari dua sisi yang berlawanan, hitam putih, halal-haram, dunia dan akhirat. Sehingga studi Islam hanya diletakkan pada aspek kajian yang bertumpu pada pembidangan keilmuan Islam, tanpa ada apresiasi baru sesuai dengan perkembangan ilmu dan teknologi. Padahal di dalam Islam sendiri tidak pernah melihat ilmu pengetahuan secara dikotomis, karena pandangan seperti ini terasa rancu oleh makna Islam sendiri. ${ }^{35}$

\section{Metode Pendekatan Studi Islam: Antara Kritik dan Tawaran}

Pengembangan studi Islam sebenarnya merupakan sebuah proses kontinuitas sejarah. Islam masa lalu adalah fundamen penting yang mewariskan dan mengembangkan kekayaan intelektual umat Islam. Lebih dari itu umat Islam adalah masyarakat yang menginternasionalkan ilmu pengetahuan. Ilmu pengetahuan Islam adalah ilmu yang dilandaskan kepada iman, kepada ajaran-ajaran Allah Swt, dan dikembangkan dengan mengambil keseluruhan warisan setelah dipisahkan mana yang benar dan mana yang salah atau yang haqq dan yang batil.

Perubahan paradigma (shifting paradigm) dari dikotomis-atomistik menuju tawaran paradigma integatifinterkonktifi," interkoneksitas dan sensitifitas antar berbagai disiplin ilmu perlu memperoleh skala prioritas dan perlu dibangun serta dikembangkan. ${ }^{37} \mathrm{D}$ engan ungkapan lain perlunya menumbuhkan etos keilmuan yang menekankan intedisiplinary, sensitivitas dan interkoneksitas antar berbagai disiplin ilmu umum dan agama. Seperti di atas dari berbagai pendekatan keilmuan yakni ilmu psikologi, filsafat, sosiologi, antropologi, dan fenomenologi digunakan untuk mendekati agama secara terpisah, maka sudah waktunya ada pendekatan interdisplinary, interkoneksitas, dan sensitifitas antar disiplin ilmu.

Pandangan semacam itu menggarisbawahi pentingnya kerangka pemikiran yang dibangun di atas fundamental dotrinedan fundametal valueyang terkandung dalam al-Q ur'an dan al-Sunnah sebagai sumber pokok. Ajaran dan nilai-nilai ilahi didudukkan sebagai sumber konsultasi yang bijak, sementara aspek-aspek kehidupan didudukkan sebagai nilai insani yang mempunyai hubungan vertikal linier dengan nilai agama. D engan ini ilmu-ilmu keislaman yang dikembangkan tidak sekedar commm sense ${ }^{38}$

Melalui uapaya semacam itu, maka pengembangan Studi Islam diharapkan mengintegrasikan nilai-nilai ilmu pengetahuan dan nilai-nilai keislaman, serta mampu

${ }^{33}$ Zakiyudin Baidhawi, IsamicStudiesn 405.

${ }^{34}$ Muhaimin hanya menggunakan Paradigma Dikotomis. Muhaimin, ParadigmaPendidkanIdam (Bandung: Rosda Karya, 2001), 39-47. Agus Maimun, "Studi Islam di Indonesia," Istiqra', Vol. 4, No. 1. (2005), 3-21.

${ }^{35}$ Azumardi Azra, Kontaks Betelog di Indonesia, Ix. Agus Maimun. "Studi Islam di Indonesia" dalam Istiqra' Jurnal Penelitian Ditperta, Vol. 4, No. 1. (2005), 3-21.

${ }^{36} \mathrm{Amin}$ Abdullah, IdamicStudiesn 405.

${ }^{37}$ Ibid.

38Jb. Connant, SäneandCommanSense(New Haven: Yale University Press, 1951). Agus Maimun, "Studi Islam di Indonesia," dalam Istiqra,21. 
melahirkan manusia-manusia yang menguasai dan menerapkan ilmu agama Islam, ilmu pengetahuan, teknologi, seni serta memiliki kematangan profesional, sekaligus hidup di dalam nilai-nilai keislaman secara kaffah

\section{Kesimpulan}

Ada beberapa hal yang perlu dicermati. Petama, pada dasarnya untuk mengkaji Islam diperlukan semacam pendekatan yang mampu menjelaskan dari mana sisi Islam dilihat. D engan begitu perdebatan khilafiah tidak akan terjadi jika masing-masing kita belajar untuk memahami dari sisi mana kita mengkaji Islam. Yang perlu ditingkatkan adalah belajar untuk memahami bukan justifikasi. Untuk sampai ke situ diperlukan seperangkat metodologi atau pendekatan yang mampu mengadakan perubahan paradigma dari dikotomis-atomistik kepada integratif interkonektif, agar studi Islam lebih "asyik" untuk dikaji.

Keedua, sesungguhnya dapat dikembangkan ilmu yang berkembang di Barat dan Islam sendiri. Kendati dasarnya berbeda namun jika masing-masing memberikan ruang untuk saling mengisi, maka studi Islam dan studi lainnya akan menemui bentuk yang pada giliranya diharapkan dapat saling mengisi satu sama lain. Ketiga, diperlukan studi lanjutan untuk menemukan karakteristik studi Islam ke-Indonesia-an karena bagaimanapun warna Islam sangat berbeda antara Islam di Barat dan Islam di Timur.

\section{Daftar Rujukan}

A hmad, K amaruzaman Bustaman. IsamHistaris, Dinamika Studi Isamd Indonesia Yogjakarta: Galang Press, 2002.

Ali, Mohammad Mumtaz. "Recontruction of Islamic Thought and Civilization: An Analitycal Study of The Movement for The Islamization of Knowledge," IsamicQuartely, Vol. XLII, No. 1, 1999.

Abdullah, Amin. Isamic Studies di Pegunuan Tingg: Pendkatan Dikotomis A tomistik-IntegatifInterkonktif. Yogyakarta:Pustaka Pelajar, 2006.

- - - - . Falsafah Kalam di Era Post Modemisme Yogyakarta: Pustaka Pelajar, 1995.

- - - - - . Stud Agama Nomativitas A tau Histaisitas Yogyakarta: Pustaka Pelajar, 1996. - - - - - . "Relevansi Studi Agama-Agama Pada Millenium Ketiga," dalam Amin

Abdullah dkk. Mencan IslamStudi Isam dengan Bedbagai Pendkkatan Yogyakarta: Tiara Wacana, 2000.

Azra, Azyumardi. Konteks Betedog di Indonesia. Bandung: Mizan, 2000.

Geertz, Clifford. TheInterpetation Of Culture Sdeted Essays New York: Basic Book, 1973. Allen, D oglas. "Phenomenologi of Religion" dalam TheRattedge Companion to TheStudy of

Rdigion ed. John R. Hinnels. G reat Britian: Routledge, tt.

Connant, JB. Siene and Comman Senæe New Haven: Yale University Press, 1951.

Dewees, D evin. "Sacred Places and Public Narratives: The Shrine of Ahmad Yasafi in Hagiographical Tradition of The Yasafi Sufi Order, 16-17 Centuries". MusimWodd 2000, Volume. 90.

Ess, Josep van. "The Beginning of Islamic Theology," dalam J.E Murdoch and E.D Stylla (ed). TheCultural Contex of Medival Leming D ordrec-Holland: Reidel Publishing, 1975. 
- - - - - . "The Logical Sructure of Islamic Theology," dalam Issa Boullata (ed). An Ontdogy of Islamic Thedogy. Canada: Mc Gill Indonesia IAIN D evelopment Project, 1992.

Fazlurahman. "Pendekatan dalam Islam dalam Studi Agama," dalam Richard Martin Pendkkatan Kajian Islam dalam Studi Agama, terj. Zakiyudin Bhaidawi. Surakarta: Muhamadiyah University Press, 2002.

Fadhl, Khalid A bu. Speakingin Gools Name Isamic LawAuthority and Women Oxford: O ne World Publication, 2001.

Fanani, Zainudin dan M. Toyibi (terj). Stud IsamAsia Tenggara Surakarta: Muhamadiyah University Press, 1999.

Golshani, Mehdi. "Islam and The Science of Nature: Some Funjdamental Q uestion", dalam Isamic Studes Vol. 39, No. 4, 2000.

Hasan, Mohd. Kamal. "Islamic Studies in Contemporary South East Asia: G eneral Observation," dalam Ismaelee (at.al), (ed). Islamic Studies in Asean. Thailand: College of Islamic Studies, Prince of Sonkla University, 2000.

al-Jabiri, Muhamad Abid. Taknin al-'Aql al-Arab. Beirut: Markaz Dirasah al-Wihdlah al'Arabiyah, 1989.

- - - - . al-Aql Siyas al-'Arabi>Beirut: Markaz al-Thaqafi>al-Arabi>1991.

- - - - - . Buryat al-'Ad al-'Arabi> Dirasah Tablilizyah Naqdiyah li Nuzumal-Mánifah fi ølThacafah al-'Arabiyah Beirut: Markaz D irasat al-Wihłlah al-'Arabiyah, 1990.

Kuhn, Thomas. The Structure of Saintific Redution Chicago: University of Chicago Press, 1970.

Lukes, Steven. EmileDurkhim His Lifeand Work. London: Pinguin Book, 1992.

Loytard, Francois. Phenomendogy. New York : State University of New York Press, 1991. Majid, Nurcholis. Tradisi Islam Peran dan Fungsinya dalam Penbangunan Indanesia Jakarta: Paramadinja, 1997.

Maimun, Agus. "Studi Islam di Indonesia", Istiqra' Jurnal Penelitian Ditperta, Vol. 4, No. 1, 2005.

Matulada "Studi Islam Kontemporer: Sintesis Pendekatan Sejarah, Sosiologi dan Antropologi dalam Mengkaji Fenomena Keagamaan," dalam Taufiq Abdulah dan M. Rusli Karim, ed. Metodbog Penditiaqn A gama: Sebuah Pengantar. Yogjakarta: Tiara Wacana, 1989.

Nasution, Harun. "Metodologi Barat Lebih Unggul," dalam Ulumal-Quran No. 3, Vol. 5, 1994.

Nata, Abudin. Metoddog Studi Isam Jakarta: Rajagrafindo Persada, 1999. Lakatos, Imre. "Falsification and The Methodology of Scientific Research Programes", dalam Critidism AndTheGrow o Knoveebe, ed. Imre Lakatos and Alan Musgrave. Cambridge: Cambridge University Presss, 1970.

Nawawi, Rifaat Syauqi. Metodblog Psikdog் Isami Yogjakarta: Pustaka Pelajar, 2000.

Nasr, Sayyed Hosein. Knovkeege and The Saced Pakistan: Suhail A kademy Lahore, 1988. Powers, D avid S. Peralihan Kekayaan dan Pditik Kdkuasaan: Kritik Histais HukumWanis terj. Arif Maftuhin. Yogjakarta: LKiS, 2001.

Popper, Karl R. TheLogicof SaietificDiscover. London: Unwin Hymann, 1987.

Salahudin, Nadhir. "Peta Kajian Islam di Indonesia", Akadknika, Volume 05, Nomor 1, 
September 1999.

Safi, Louay. TheFoundation of Knowteede A Comparative Study in Istamic and Westem Methode of Inquiry. Malaysia: International Islamic Universwity Malaysia Press, 1996.

Safi, O mit. "Bargaining with Barakah: Persian Sufism Mysticism and Pre Modern Politics," dalam MusimWordd 2000, Volume. 90.

Stokhof, W.A.L. dan N.J.G. Kaptein (Red). Be̋rapa Kajian Indonesia dan Isam Jakarta: INIS, 1990.

Wandenburg, Jacques. "Studi Islam di Belanda," dalam Nanji Azim, ed. Pła Stud Islam Orientalisme dan Arah Baru Kajian Isam d Barat. Bantul: Fajar Pustaka Baru, 2003. 